\title{
Recurrent Pulseless Ventricular Tachycardia Induced by Commotio Cordis Treated with Therapeutic Hypothermia
}

\author{
Sanghyun Lee, M.D. ${ }^{1}$, Hyunggoo Kang, M.D. ${ }^{1}$, Taeho Lim, M.D., Ph.D. ${ }^{1}$, Jaehoon Oh, M.D., Ph.D. ${ }^{1}$, \\ Chiwon Ahn, M.D. ${ }^{1}$, Juncheal Lee, M.D. ${ }^{1}$, and Changsun Kim, M.D. ${ }^{2}$ \\ 'Department of Emergency Medicine, Hanyang University College of Medicine, Hanyang University Hospital, Seoul; \\ ${ }^{2}$ Department of Emergency Medicine, Hanyang University Guri Hospital, Guri, Korea
}

The survival rate of commotio cordis is low, and there is often associated neurological disability if return of spontaneous circulation (ROSC) can be achieved. We report a case of commotio cordis treated with therapeutic hypothermia (TH) that demonstrated a favorable outcome. A 16-year-old female was transferred to our emergency department (ED) for collapse after being struck in the chest with a dodgeball. She has no history of heart problems. She was brought to our ED with pulseless ventricular tachycardia (VT), and ROSC was achieved with defibrillation. She was comatose at our ED and was treated with $\mathrm{TH}$ at a target temperature of $33^{\circ} \mathrm{C}$ for 24 hours. After transfer to the intensive care unit, pulseless VT occurred, and defibrillation was performed twice. She recovered to baseline neurologic status with the exception of some memory difficulties.

Key Words: commotio cordis; tachycardia; therapeutic hypothermia; ventricular; thoracic injury.

Commotio cordis is defined as a cardiac arrest resulting from a blunt trauma to the chest wall in a patient who has no history of structural cardiac disease. The mean age of patient is 13.6 years and it occurs most commonly in young males.[1] The mechanism of injury is often a sports-related projectile: baseball, soft ball, ice hockey or a blow to the chest wall from another player, etc.[2]

The rate of mortality for this phenomenon is high, and the most common rhythm after collapse was ventricular fibrillation (VF).[1,3,4] It could occur by low-energy trauma to the chest wall and the precise timing of the impact is closely related to the occurrence of VF.[5]

Therapeutic hypothermia (TH) is a neuro-protective strategy for cardiac arrest patient who has persistent neurologic compromise after return of spontaneous circulation (ROSC). Current guideline recommended to use TH in adult cardiac arrest when the initial rhythm is VF.[6] There is a controversy in use of TH in arrest patient with non-cardiac causes of VF arrests.

We report a case of recurrent pulseless ventricular tachycardia induced by commotio cordis treated with TH and good neurologic outcome.

Received on August 4, 2015 Revised on September 24, 2015 Accepted on October 8, 2015

Correspondence to: Hyunggoo Kang, Department of Emergency Medicine, Hanyang University College of Medicine, Hanyang University Hospital, 222-1 Wangsimni-ro, Seongdong-gu, Seoul 04763, Korea

Tel: +82-2-2290-9291, Fax: +82-2-2290-9280 E-mail: emer0905@gmail.com

*No potential conflict of interest relevant to this article was reported.

\section{Case Report}

A 16-years-old female was transferred to our emergency department (ED) for management of post-cardiac arrest syndrome from other hospital. She has no structural heart problem and arrhythmia on past medical history. Three hours 

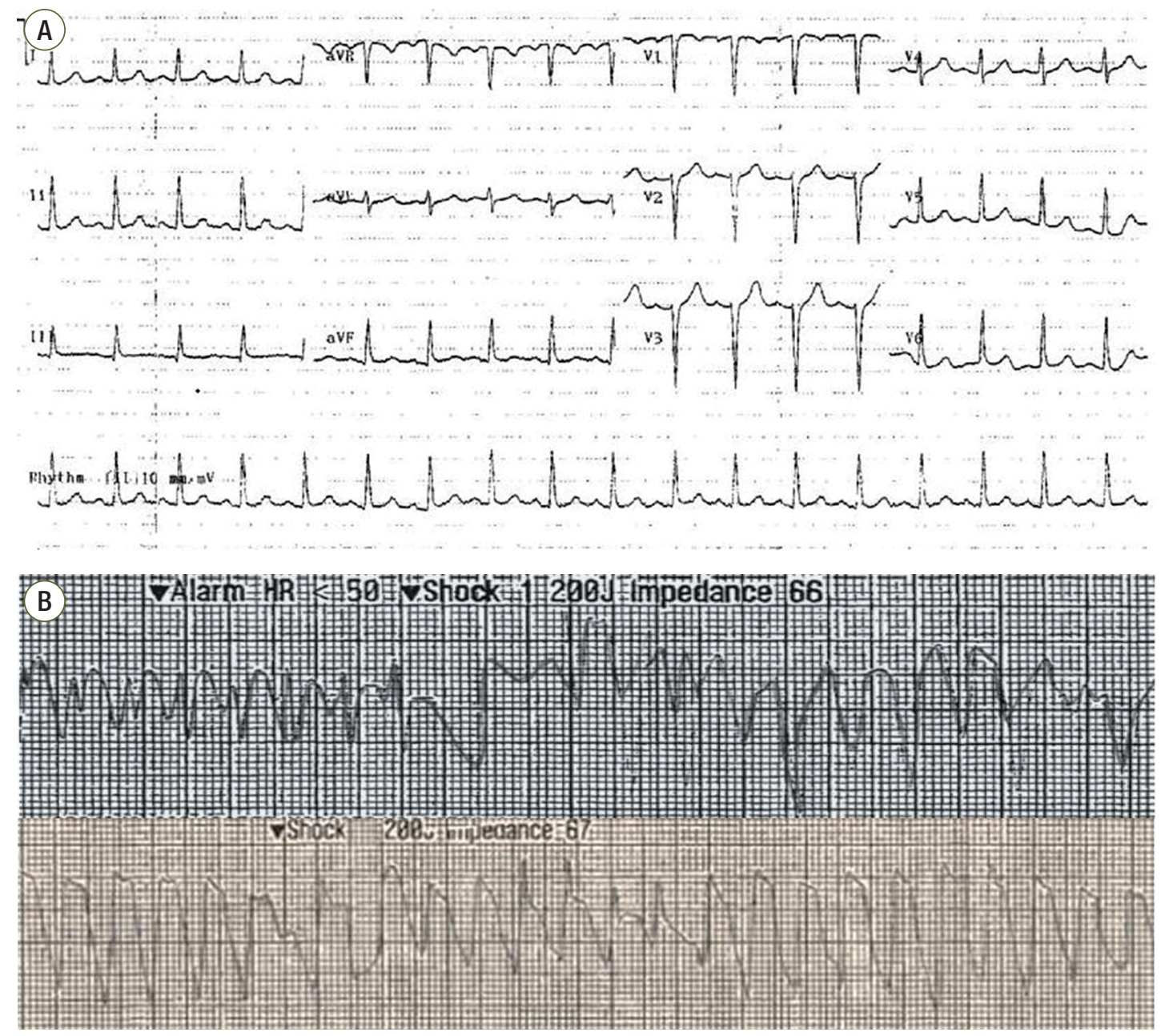

Fig. 1. Serial findings of electrocardiography. (A) An electrocardiograph at another emergency department showed sinus tachycardia (heart rate $=107$ beats/minutes) (B) Pulseless ventricular tachycardia was shown, for which a shock of 200J was immediately administered.

before our hospital arrival, the patient was playing a dodge ball game, when she was struck over the anterior chest wall by a dodge ball. After struck by a dodge ball, she fell to the ground immediately, and lost consciousness according to witness. The witness activated emergency medical service and performed cardiopulmonary resuscitation (CPR). After 3 minute, the paramedics arrived at the scene and started $\mathrm{CPR}$. The rhythm was asystole on monitor and they did not apply an automated external defibrillator. About 15 minutes after collapse, the patient arrived at local ED and initial rhythm was pulseless ventricular tachycardia (VT) and epinephrine $1 \mathrm{mg}$ was injected. After 5 minutes CPR, after ROSC was achieved. The total time from collapse to ROSC was approximately 20 minutes. After ROSC is achieved, there were no spontaneous respiration, and ventilator was applied. The vital signs were heart rate of 133 beats/minute, blood pressure of 134/89 mmHg. An eletrocardiography (ECG) showed sinus tachycardia and heart rate was about 107 beats/minutes (Fig. 1). The results of a complete blood cell count showed a white blood cell count of 20,000/ $\mathrm{mm}^{3}$, hemoglobin level of $15.5 \mathrm{~g} / \mathrm{dL}$, and platelet count of $276,000 / \mathrm{mm}^{3}$. The result of coagulation tests showed a prothrombin time of $101 \%$ (International Normalized Ratio 0.99 ) and activated partial prothrombin time of 334 seconds. Renal function test and electrolyte results were as following values: blood urea nitrogen, $10.9 \mathrm{mg} / \mathrm{dL}$; creatinine, 0.74 $\mathrm{mg} / \mathrm{dL}$; sodium, $139 \mathrm{mEq} / \mathrm{L}$; potassium, $3.2 \mathrm{mEq} / \mathrm{L}$ : chloride, $105 \mathrm{mEq} / \mathrm{L}$; and total $\mathrm{CO}_{2}, 105 \mathrm{mEq} / \mathrm{L}$. Liver function 


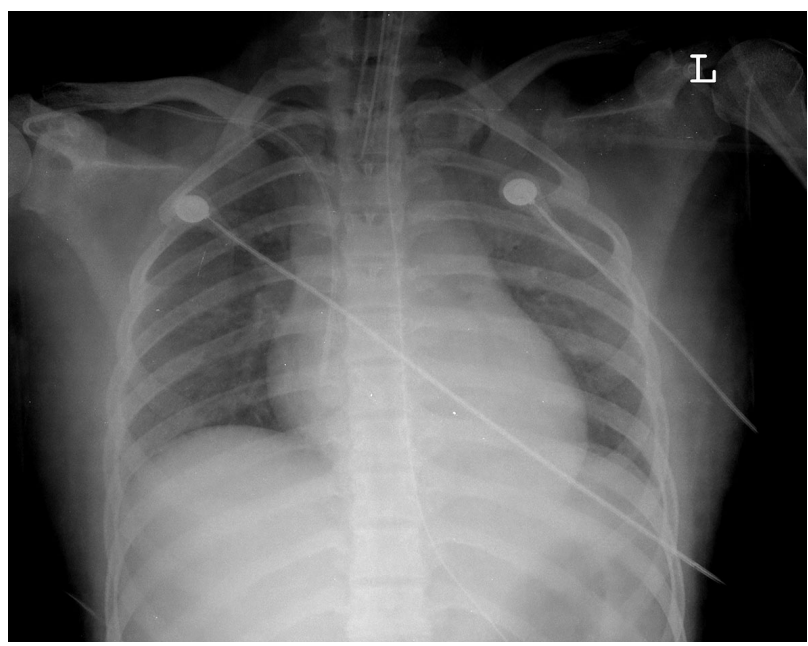

Fig. 2. Chest radiography findings. Chest radiograph on hospitalized day 1 showing diffuse opacity on both lung fields. This finding was consistent with bilateral pulmonary edema.

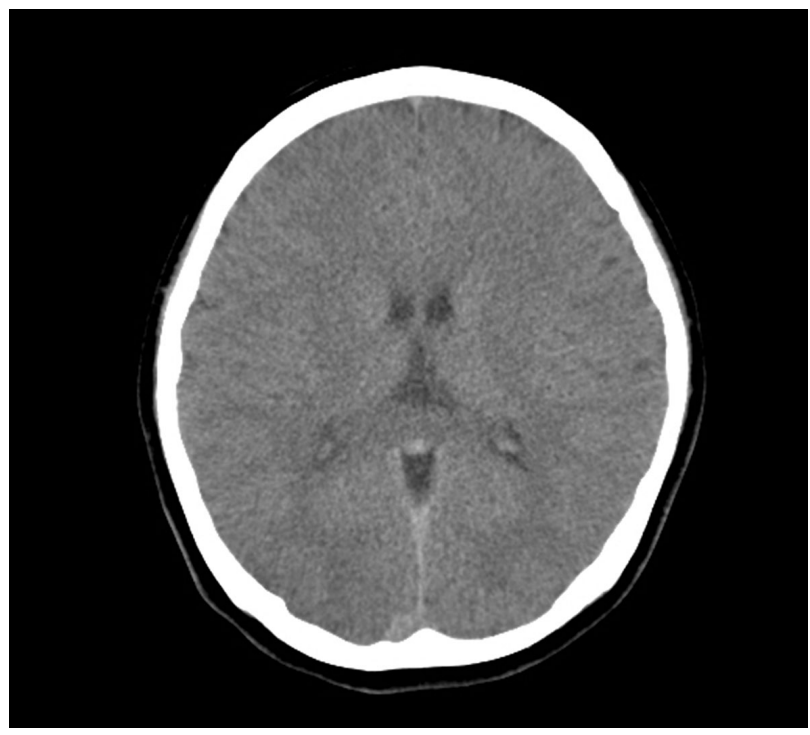

Fig. 3. The findings of brain computed tomography. Brain computed tomography on hospitalized day 2 showed an attenuation of lobar gray-white matter differentiation.

tests showed a total bilirubin value of $0.20 \mathrm{mg} / \mathrm{dL}$; an aspartate aminotransferase of $9.0 \mathrm{U} / \mathrm{L}$; and an alanine transaminase of $88 \mathrm{U} / \mathrm{L}$. Troponin-I was $0.01 \mathrm{ng} / \mathrm{mL}$, and Creatine Kinase MB Isoenzyme was $1.0 \mathrm{ng} / \mathrm{mL}$. About 90 minutes after ROSC, the patient transferred to our ED for management of post-cardiac arrest syndrome. At arrival to our ED, she was sedated by continuous infusion of midazolam and vecuronium bromide, and her vital signs were body temper- ature of $34.7^{\circ} \mathrm{C}$ heart rate of 130 beats/minute, blood pressure of $134 / 102 \mathrm{mmHg}$, and $\mathrm{O}_{2}$ saturation of $100 \%$ on $100 \%$ oxygen via bag valve mask. She did not response to noxious stimuli and pupil sizes of right/left eyes were $0.7 / 0.7 \mathrm{~cm}$, and the pupil reflection was intact on both eyes. Her ECG showed atrial fibrillation and heart rate is about 84 beats per minute. Pulmonary edema was observed on chest radiograph (Fig. 2). TH was initiated in ED and she transferred to intensive care unit (ICU). After arrival to ICU, 2 times of pulseless VT were occurred, and ROSC was achieved after CPR (about 12 minutes) and 4 times of defibrillation and amiodarone $300 \mathrm{mg}$ injection (Fig. 1). Then, amiodarone $360 \mathrm{mg}$ was injected over 6 hours, followed $540 \mathrm{mg}$ over the next 18 hours. Her blood pressure was low after intravenous loading of $1 \mathrm{~L}$ normal saline and norepinephrine was injected continuously at the rate of $7 \mathrm{mcg} / \mathrm{min}$. CoolGard/ Coolline ${ }^{\mathrm{TM}}$ catheter system (ZOLL, Chelmsford, USA) were used to cool the patient to a target temperature of $33^{\circ} \mathrm{C}$. The target temperature was reached 2 hours after cooling was initiated, which was 6 hours after cardiac arrest. Therapeutic hypothermia was maintained for 24 hours, and then patient was rewarmed over a period of 15 hours.

Brain CT was done on hospitalized day (HD) 1, and showed an attenuation of lobar gray-white matter differentiations (Fig. 3). Echocardiography on HD 3 showed slightly decreased global left ventricle systolic function and apical dyskinesia (ejection fraction is about $48.974 \%$ ) HD 4, she responded to verbal stimulus and weaning of ventilator was done and the patient was extubated. On HD 4, electrocardiography showed accelerated junctional rhythm with atrioventricular dissociation and heart rate was about 90 beats per minute. The rhythm converted to normal sinus rhythm spontaneously without special treatment. Troponin-I was 0.16 $\mathrm{ng} / \mathrm{mL}$ on admission day and increased to $0.29 \mathrm{ng} / \mathrm{mL}$ on $\mathrm{HD}$ 3 and $0.06 \mathrm{ng} / \mathrm{mL}$ on HD 5. Levels of neuron specific enolase were $41.8 / 33.5 / 37.8 \mathrm{ng} / \mathrm{mL}$ on HD $1 / 2 / 3$. She had returned to her baseline neurologic status, with the exception of mild short-term memory disturbances noted by her family. She was transferred to other hospital to evaluate another cause of recurrent VT on HD 8. She admitted to other hospital for 7 days, and several studies were performed. There were no abnormal findings on percutaneous coronary angiography, Holter monitoring and electrophysiologic study. On HD 7, she discharged and followed up outpatient hospital. 


\section{Discussion}

Commotio cordis is a very rare syndrome of mechanicalelectrical arrhythmia. Only, 2 cases of VF arrests occurred by low energy fist blow to the chest wall and traffic accident were reported in Korea in our knowledge.[7,8] And, the exact mechanism of commotio cordis is incompletely understood. The important factors influence the occurrence of commotio cordis: 1) The location of the impact to the chest wall, 2) the timing of the impact with respect to the cardiac cycle. It is associated to induce VF that impact occurs directly to the center of the heart, rather than at the apex, base or other part of the precordium.[9] The impact occurred between 15 and $30 \mathrm{msec}$ before the peak of the T wave was associated with VF causing commotio cordis in an experimental model using pigs.[5] The energy of impact could be an another important variable in the generation of commotio cordis. In animal study, impacts at $64 \mathrm{~km} /$ hour were more likely to produce VF than impacts with greater or lesser velocities. [10] In general, commotio cordis impacts are typically of low-energy and velocity.[5] The most common rhythm of commotio cordis was VF.[11-13] Complete heart block, idioventricular rhythm, atrial fibrillation were reported. $[11,14,15]$ In this case, arrest rhythm was a recurrent VT. We thought the mechanism of VT could be similar to that of VF.

The number of reported cases of commotio cordis has dramatically increased over the last years, it would be due to increased awareness of this condition. Since the National Commotio Cordis Registry was established, over 200 confirmed cases of commotio cordis have been reported.[16,17] Still, it is probable that the actual number of cases is greater than reported because of the lack of awareness of commotio cordis and underreporting to the National Commotio Cordis Registry. There were no significant differences in demographics and survival rate between patients in the US and outside the US, though non-US patients were somewhat order (mean 19/15 years in US/non US). To see the result of autopsy, no acute or chronic cardiac abnormality, or damage to the ribs, sternum or heart has been found that would account for the sudden death. An absence of structural cardiac injury is a key point to distinguish commotio cordis from cardiac contusion, in which high-impact blows result in traumatic damage to myocardial tissue and the overlying structures of thorax.[8]

Current guideline recommended that comatose adult patients with ROSC after out-of-hospital VF cardiac arrest should be cooled at $32-34^{\circ} \mathrm{C}$ for 12 to 24 hours (Class I, LOE B).[6] TH could be neuro-protective by slowing oxygen consumption and delays the cytotoxic damage in anoxic brain injury.[18-20] There were controversies in applying $\mathrm{TH}$ in patients with no-cardiac causes of VF arrests. There were several reports about using therapeutic hypothermia other than VF cardiac arrest: traumatic brain injury, stroke, commotio cordis, etc.[8,19] There were several complications of TH: cardiac dysrhythmias, sepsis, coagulopathy.[18] There were no special complications associated with $\mathrm{TH}$ in our case. We believed that the benefits of using TH outweighted the risks of it in arrest caused by other cause than VF cardiac arrest.

Anoxic brain injury is the common pathway from cardiac arrest caused by various causes. The pathophysiology of anoxic brain injury is similar and the morbidity and mortality are universally high. TH is recommended in cardiac caused VF arrest, [6] we thought that it could be considered to use for VT arrest secondary to commotio cordis. This case illustrates that using $\mathrm{TH}$ for patient presented with commotio cordis could be profitable.

\section{Acknowledgements}

The authors would like to thank Younje Lee for willingness to participate and evaluation of the manuscript.

\section{ORCID}

$\begin{array}{ll}\text { Sanghyun Lee } & \text { http://orcid.org/0000-0002-4987-285X } \\ \text { Hyunggoo Kang } & \text { http://orcid.org/0000-0002-9522-2532 } \\ \text { Taeho Lim } & \text { http://orcid.org/0000-0003-2555-5697 } \\ \text { Jaehoon Oh } & \text { http://orcid.org/0000-0001-8055-1467 } \\ \text { Chiwon Ahn } & \text { http://orcid.org/0000-0002-1813-1098 } \\ \text { Juncheal Lee } & \text { http://orcid.org/0000-0003-3058-4759 } \\ \text { Changsun Kim } & \text { http://orcid.org/0000-0001-8475-3453 }\end{array}$




\section{References}

1) Maron BJ, Gohman TE, Kyle SB, Estes NA 3rd, Link MS: Clinical profile and spectrum of commotion cordis. JAMA 2002; 287: 1142-6.

2) Maron BJ, Ahluwalia A, Haas TS, Semsarian C, Link MS, Estes NA 3rd: Global epidemiology and demographics of commotion cordis. Heart Rhythm 2011; 8: 1967-71.

3) Maron BJ, Doerer JJ, Hass TS, Estes NA, Hodges JS, Link MS: Commotio cordis and the epidemiology of sudden death in competitive lacrosse. Pediatrics 2009; 124: 996-71.

4) Maron BJ, Poliac LC, Kaplan JA, Mueller FO: Blunt impact to the chest leading to sudden death from cardiac arrest during sports activities. N Engl J Med 1995; 333: 337-42.

5) Link MS, Wang PJ, Pandian NG, Bharati S, Udelson JE, Lee MY, et al: An experimental model of sudden death due to low-energy chest-wall impact (commotion cordis). N Engl J Med 1998; 338: 1805-11.

6) Peberdy MA, Callaway CW, Neumar RW, Geocadin RG, Zimmerman JL, Donnino M, et al: Part 9: postcardiac arrest care: 2010 American Heart Association guidelines for cardiopulmonary resuscitation and emergency cardiovascular care. Circulation 2010; 122(18 Suppl 3): S768-86.

7) Park HS, Han SW, Cho YK, Yun HJ, Lee YS, Hyun DW, et al: A case of commotio cordis. Korean Circ J 2003; 33: 719-22.

8) Jo UR, Park SM, Lee KJ, Lee YH, Ahn JY, Sohn YD, et al: Comotio cordis by a traffic accident visited the emergency department. J Korean Soc Emerg Med 2014; 25: 484-8

9) Link MS, Maron BJ, VanderBrink BA, Takeuchi M, Pandian NG, Wang PJ, et al: Impact directly over the cardiac silhouette is necessary to produce ventricular fi- brillation in an experimental model of commotio cordis. J Am Coll Cardiol 2001; 37: 649-54.

10) Link MS, Maron BJ, Wang PJ, VanderBrink BA, Zhu W, Estes Nar 3rd: Upper and lower limits of vulnerability to sudden arrhythmic death with chest-wall impact (commotio cordis). J Am Coll Cardiol 2003; 41: 99104.

11) Kaplan JA, Karofsky PS, Volturo GA: Commotio cordis in two amateur ice hockey players despite the use of commercial chest protectors: case reports. J Trauma 1993; 34: 151-3.

12) Abrunzo TJ: Commotio cordis. The single, most common cause of traumatic death in youth baseball. Am J Dis Child 1991; 145: 1279-82.

13) Dickman GL, Hassen A, Luckstead EF: Venticular fibrillation following baseball injury. Phys Sport Med 1978; 6: 85-6.

14) Green ED, Simson LR Jr, Kellerman HH, Horowitz RN, Sturner WQ: Cardiac concussion following softball blow to the chest. Ann Emerg Med 1980; 9: 155-7.

15) Ota K, Bratincsak A: Atrial fibrillation induced by commotio cordis secondary to a blunt chest trauma in a teenage boy. Pediatrics 2015; 135: e199-210.

16) Maron BJ, Estes NA 3rd: Commotio cordis. N Engl J Med 2010; 362: 917-27.

17) Link MS: Commotio cordis: ventricular fibrillation triggered by chest impact-induced abnormalities in repolarization. Circ Arrhythm Electrophysiol 2012; 5: 425-32.

18) Hammer MD, Krieger DW: Hypothermia for acute ischemic stroke: not just another neuroprotectant. Neurologist 2003; 9: 280-9.

19) Olsen TS, Weber UJ, Kammersgaard LP: Therapeutic hypothermia for acute stroke. Lancet Neurol 2003; 2: 410-6.

20) Auer RN: Non-pharmacologic (physiologic) neuroprotection in the treatment of brain ischemia. Ann N Y Acad Sci 2001; 939: 271-82. 